\title{
Improving Undergraduate Ophthalmology Education in the Time of COVID-19 Pandemic by Video-Assisted Online Learning
}

\author{
Muhammad Syauqie* and Hendriati \\ Department of Ophthalmology, Faculty of Medicine, Andalas University, Indonesia \\ *Corresponding author: Muhammad Syauqie, Department of Ophthalmology, Faculty of Medicine, Andalas University, \\ West Sumatra, Indonesia
}

\section{ARTICLE INFO}

Received: 齒 July 05, 2021

Published: 幽 July 15, 2021

Citation: Muhammad Syauqie, Hendriati. Improving Undergraduate Ophthalmology Education in the Time of COVID-19 Pandemic by Video-Assisted Online Learning. Biomed J Sci \& Tech Res 37(2)-2021. BJSTR. MS.ID.005968.

Keywords: Ophthalmology Education; Video-Assisted Online Learning; Covid-19; Blended Learning; I Learn

\begin{abstract}
Introduction: The COVID-19 pandemic had forced many institutions to diminished face-to-face teaching classes. We conduct an online teaching method through an e-learning platform during the pandemic to ensure that the students attain the basic competencies. This study aimed to give an insight into the efficacy of online learning in undergraduate ophthalmology education.
\end{abstract}

Methods: This was an interventional study in a university teaching hospital, and 64 medical students participated in this study. The students were instructed to watch the clinical skill video and make a case report through the e-learning platform. The students completed the multiple-choice test and the student perception questionnaire during the online period. The students then continue to undergo two weeks of in-person clinical clerkship, and at the end of the rotation, the students had an objective structured clinical examination test using simulated patients.

Results: The mean score of multiple choice and clinical examination test was $72,50+12,54$ and 89,80+6,66, respectively. There also improvement in knowledge and skill about visual acuity and subject refractive examination at the end of the clinical clerkship period. About $85.93 \%$ of students were satisfied with online learning quality, but $95.31 \%$ of students stated that clinical skills were easier to understand if demonstrated directly by the instructor.

Conclusions: This study results can encourage that video-assisted online learning models can be useful as an adjunct for improving undergraduate students' basic ophthalmology skills before they entered clinical clerkship. Quality assurance of the video resource should be done to ensure that students can achieve basic ophthalmology competencies.

\section{Introduction}

The COVID-19 pandemic had given an immediate challenge to traditional undergraduate medical education methods, and in-person clinical clerkships, including ophthalmology rotation for medical students, had been suspended to prevent the threat of disease transmission. This rotation cancellation could lead to a lack of patient's exposure and, eventually, inadequate basic ophthalmology knowledge and clinical skills. The lack of ophthalmology case exposures in medical students will contribute to the misdiagnosis and mismanagement of ocular diseases and inappropriate referral to ophthalmologist [1,2]. This condition forced the need to develop virtual clinical learning. The online learning method is not a substitute for traditional face-to-face learning method and is not without its shortcoming, but it can help to ensure that the medical students would not lose their precious time and could continue with their academics in these uncertain times $[3,4]$. 
Our university had developed an online learning platform named iLearn before the outbreak of COVID-19, but its use was still limited. The COVID-19 pandemic then allows us to explore a new approach for teaching-learning techniques using this online learning platform. Adequate evidence-based research must be provided to encourage the faculty to implement this alternative learning method during this pandemic period [5,6]. Therefore, we conducted this study to evaluate the online learning method's effectiveness during the COVID-19 pandemic for undergraduate medical students in ophthalmology clinical clerkships. This study will give an insight into the efficacy of online learning in undergraduate ophthalmology education.

\section{Methods}

This study was conducted from June to November 2020 at the Department of Ophthalmology of Faculty of Medicine Andalas University, Indonesia. This study design was an interventional study. The online learning platform we used to conduct the online learning was the iLearn. This study enrolled 64 medical students who enter virtual clerkship in ophthalmology rotation during the COVID-19 pandemic for about four weeks. The students had never been undergone face-to-face clinical clerkship in the Department of Ophthalmology previously. Another inclusion criteria were clinical clerkship students who still registered as medical students and clinical clerkship students who had iLearn platform personal account. Exclusion criteria were clinical clerkship students who did not complete the multiple-choice test and the student perception questionnaire.

The students were instructed to enter the iLearn platform and do several tasks, including watching the clinical skill video and making a report about the case presented in the video, filling the multiple-choice question (MCQ) test and the student perception questionnaire through the iLearn platform. The clinical skill video topics include:

a) Visual acuity examination and introduction of ophthalmology examination tools.

b) History taking and subjective refractive examination.

c) Eyelid infection case presentation.

d) Conjunctival infection case presentation.

After watching the clinical skill videos, making the case reports, and answering the multiple-choice test, the students fill a questionnaire comprising ten questions about their perception of online learning. After two weeks of online learning, the students then undergo two weeks of in-person clinical clerkship in the university hospital wearing personal protective equipment, which is mandatory. At the end of the ophthalmology rotation, the students undergo an objective structured clinical examination (OSCE) test with the simulated patients, including visual acuity and subjective refractive examination. All data were collected and analyzed computerized using the descriptive statistic method. The authors then withdraw the conclusion from the result. This project was deemed quality improvement and research ethics approval was waived.

\section{Results}

The demographic data of the medical students are following. Among 64 students, 52 were female $(81,25 \%)$ and 12 were male $(18,75 \%)$. The range of students ages was 19 years old to 28 years old with a mean age was 22,66 years old. Assessment and evaluation of the online learning method are done by observing the MCQ and OSCE test scores and the students' perception questionnaire results. By assigning this type of assessment, we can know the medical students' level of basic knowledge and skills in ophthalmology. Table 1 shows the mean score of the MCQ and OSCE tests Table 1. Mean score of multiple choice and objective structured clinical examination test. From the test result, it can be seen that the students get good test scores both in MCQ and OSCE tests. However, in the MCQ test, the knowledge about visual acuity and subjective refractive examination still poor, shown by the low mean score. Nevertheless, later in the OSCE test, the student's skill in visual acuity and subjective refractive examination had improved a lot, shown by the increase of the mean score.

Table 1: Mean score of multiple choice and objective structured clinical examination test.

\begin{tabular}{|c|c|}
\hline Test & Mean Score \\
\hline MCQ test & $72,50+12,54$ \\
\hline $\begin{array}{c}\text { Visual acuity and subjective refractive examination } \\
\text { score in MCQ test }\end{array}$ & $55,55+22,20$ \\
\hline OSCE test & $89,80+6,66$ \\
\hline $\begin{array}{c}\text { Visual acuity and subjective refractive examination } \\
\text { score in OSCE test }\end{array}$ & $86,06+8,43$ \\
\hline
\end{tabular}

Figure 1 shows the perception of the medical student about online learning methods. From the questionnaire results, the majority of the students agree that the videos were well-prepared, and the contents were easily understood. The videos also help the students to achieve learning objectives in clinical ophthalmology clerkship. However, some students prefer the face-to-face learning methods, especially in acquiring basic ophthalmology skills, with the direct supervision of an ophthalmologist. A clinical skill directly demonstrated by the instructor will be easier to understand and perform according to most students. 


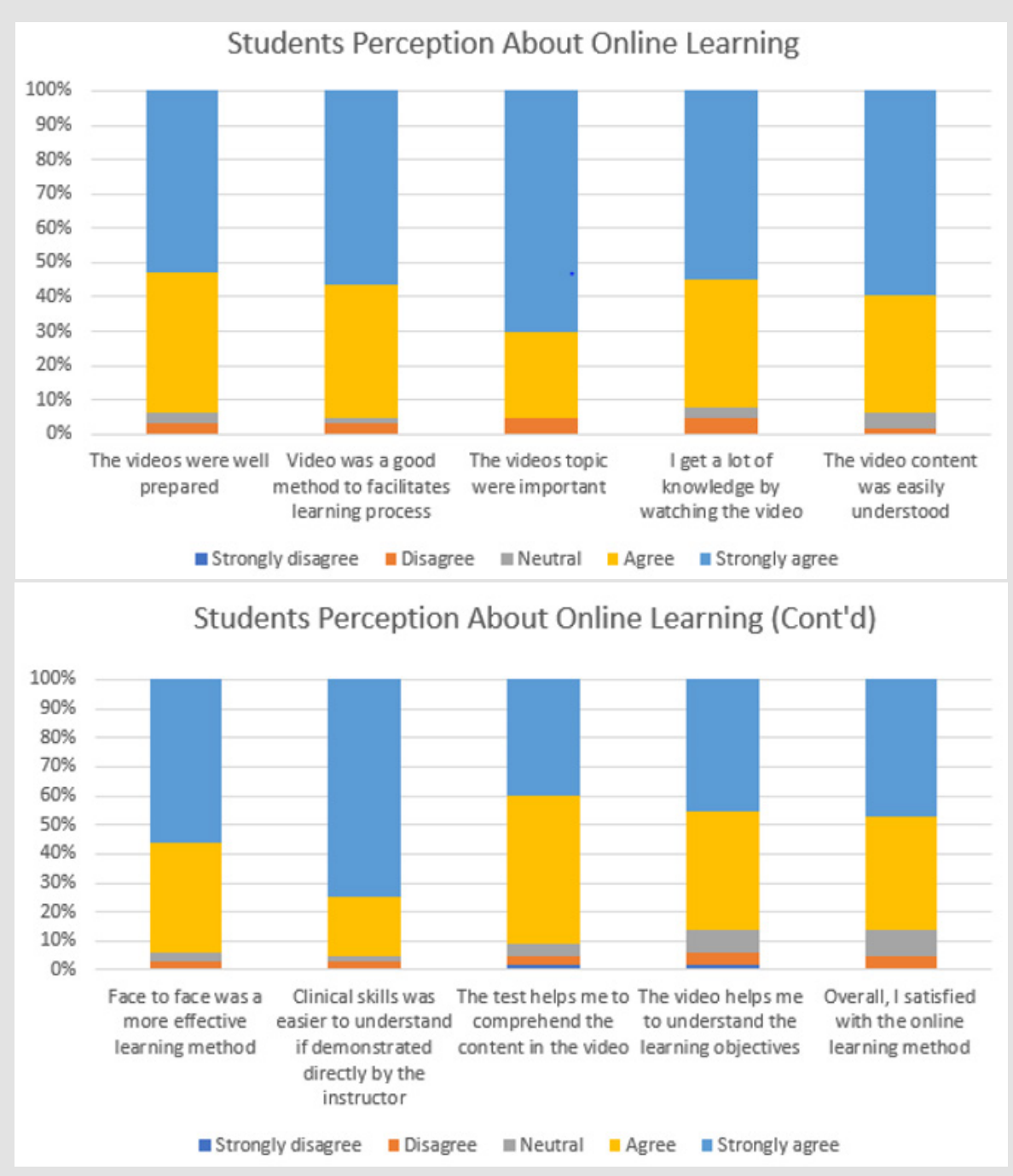

Figure 1: Students' perception about online learning.

\section{Discussion}

The decline in undergraduate ophthalmology education level for medical students, which was further severed by the COVID-19 pandemic, could lead to a lack of essential basic skills in ophthalmology examination among medical students. The applied physical distancing and lockdown strategy had interfered with the learning-teaching process in most countries in the world. The medical students have been targeted to achieved some competencies in ophthalmology, but the current situation made it difficult because there were diminished opportunities and times to encounter real patients in the hospital. Modification of the ophthalmology teaching method must take place to accommodate this task within a shorter period. The advancement of information technology had brought online learning as one of the best alternative teaching methods during this pandemic era to get sufficient competencies in ophthalmic skills and knowledge [7-9].
Before the pandemic period, undergraduate ophthalmology rotation took four weeks in our department. The learningteaching process involves face-to-face case discussion and direct observation of patient examination in the outpatient clinic. During the COVID-19 pandemic, the education process had shifted into half of online learning and half of in-person clerkship. This change is to reduce the number of students in our department where the student's group was split into halves so the physical distancing is still can be applied. This study result gives a promising result about the implementation of online learning in undergraduate ophthalmology education. Overall, both MCQ and OSCE tests show good mean scores of the students. A concern must be given to basic ophthalmology skill which is more complicated for medical students to master such as subjective refractive examination. In the online learning period, the students still difficult to comprehend this issue, shown by a low mean score of the MCQ test $(55,55+$ $22,20)$. However, after undergoing two weeks of in-person clinical 
clerkship in the university hospital, the skill of the students in the subjective refractive examination had improved significantly. Comprehensive management of simple refractive errors is one of the basic competencies in ophthalmic skill, which is mandatory to primary care physicians according to the National Standard of Indonesian Medical Doctor Competencies [10]. Unfortunately, the subjective refractive examination is quite difficult to master by the medical students. This examination needs patience and repetitive practice in order to do it well and get an accurate refractive error measurement. Besides that, this examination needs a cooperative patient and does not enough by only watching an educational video. In the in-person clinical clerkship period, the students had an opportunity to practiced it under the supervision of an ophthalmologist and directly get feedback after the examination. Feedback holds an important role in improving the student's clinical skill as it guides them to do the procedure according to the standards. Therefore, face-to-face learning methods are still a more effective means of teaching for this particular ophthalmic skill $[7,11]$.

Overall, the student's perception was good about online learning, where more than $85 \%$ of students were satisfied with the quality of online learning. About $85,94 \%$ of students also can comprehend the learning material in the video and achieved the learning objectives which were expected. More than $90 \%$ of the students agreed that the topic presented in online learning was an essential topic to learned and very useful in clinical practice as a primary care physician. However, many of the students $(93,75 \%)$ stated that face-to-face learning methods were more effective than online learning methods, especially in learning clinical skills such as subjective refractive examination. About $95,31 \%$ of them considered that clinical skills that the instructor directly demonstrated will be easier to understand and can rehearse to perform under the direct supervision of an ophthalmologist. Few studies about perception about online undergraduate ophthalmology teaching during the COVID-19 pandemic had shown positive feedback from students. Majority of the students perceived that online learning was a favorable alternative to the conventional face-to-face learning method with the ease of flexibility of the learning process to time and place, repeatability of the learning material at own pace, and the more courage to ask and interact with the instructor. The shortcomings of online learning were mainly the lack of clinical training and patient encounter, the learning process was not as interactive as traditional face-to-face learning, and limited facilities include poor internet connectivity [2,12-14].

Provision of learning materials included clinical skill videos before undergraduate ophthalmology clinical clerkship had shown to significantly improved subjective and objective measures of knowledge and skill performance. This effect is likely due to the specified topics and the higher efficacy of selected materials provided by the instructor relative to student-selected materials so the students can focus and concentrate on achieving the learning objectives and clinical skills expected [15]. Computerassisted learning modules using virtual patients have been applied to enhance teaching and learning by allowing medical students to sharpen their clinical reasoning skills by formulating a diagnosis and treatment plan on virtual patients with simulated eye conditions in a safe learning environment before practicing on real patients. The application of virtual patients resulted in increased academic performance and sustained retention over traditional teaching alone [16]. However, such particular skills, such as refractive error correction and direct ophthalmoscopy, still need real patients to practice in order to understand the correct angle of approach and the necessary adjustments to be made during the examination. A hybrid learning model of virtual didactics, simulation, telemedicine, self-directed learning, and in-person clinical encounters will provide students with various experiences, including new opportunities in patient care and technical skill development $[1,17]$. This study shows that despite the excellent score of the overall multiple-choice test, the students still have inadequate knowledge about visual acuity and subjective refractive examination topics during the online learning period. However, after their encounter real patients and practiced directly in the clinic during the in-person clinical clerkship period, their knowledge and skill about visual acuity and subjective refractive examination topic have improved dramatically in the OSCE test at the end of the period.

Before the pandemic, the learning process in medicine is still commonly based on a conventional clerkship approach where learners observe clinical practice and learn from hands-on activity when permitted by the clinical instructor. We are forced to use online learning to teach clinical ophthalmology during the pandemic to limit unnecessary face-to-face exposure. Nevertheless, online learning cannot permanently replace in-person clinical clerkship. In-person ophthalmology clerkship enhances our ability to observe students and evaluate clinical performance, including students' integration into the healthcare team, skills in interacting with patients, professionalism, and clinical and surgical skills. To overcome the shortcomings of online learning in clinical ophthalmology, we transformed our undergraduate ophthalmology curriculum into blended learning, where online learning is combined with traditional face-to-face learning. In the online learning period, the students enrolled in the iLearn platform and were assigned to watch the clinical skill videos, complete the multiple-choice test, and make a case report. In the clinical clerkship period, the students came to the teaching hospital wearing personal protective equipment, which is mandatory. The students can observe the real patient examination directly in the outpatient clinic. Afterward, the instructor gives an explanation 
and discussion about the patient examined before. The students were also performed basic ophthalmology examinations under the supervision of the instructor. As an adjunct to conventional learning method, however, online learning may be beneficial and may have a significant impact on future medical students, including new opportunities in patient care and technical skill development $[1,18-21]$.

This study's limitations include the relatively small sample size and the self-reported nature of the questionnaire in which participants may be subject to reporting bias affected by student confidence and the degree to which they did not want to disappoint teaching staff. This study also does not compare the blended learning method's outcome with the conventional full-time clinical clerkship. However, with reasonable satisfaction from most students in this study, we hope that online learning can supplement the in-person clinical clerkship method, especially in this pandemic period, to ensure that the students would not lose precious time and could continue with their academics.

\section{Conclusion}

This study results can encourage that a blended learning model, which combines video-assisted online learning with the inperson clinical clerkship, can be useful for acquiring clinical skills by health students. Learning process flexibility to time and place was the most advantage of online learning and lacking to perform clinical skills was the main shortcoming. Quality assurance of the video resource should be done to enable students to understand the context and engage with video resources so in time they encounter real patients, they are already prepared and gain sufficient competencies. The advanced development of information and communication technology will further be improved and established online learning as a more time- and resource-effective model for the interactive and integrated learning process.

\section{Acknowledgment}

This work was supported by a grant from the quality assurance and education body of Andalas University.

\section{Conflict of Interest}

The authors declare that there is no conflict of interest.

\section{References}

1. Andrew T Duong, Sarah H Van Tassel, Ana G Alzaga Fernandez, Abha Amin, Nisha Chadha, et al. (2020) Medical Education and Path to Residency in Ophthalmology in the COVID-19 Era: Perspective from Medical Student Educators, Ophthalmology. Elsevier127(11): e95-e98.

2. Rouli Sud, Pallavi Sharma, Vaishali Budhwar, Sumeet Khanduja (2020) Undergraduate ophthalmology teaching in COVID-19 times: Students' perspective and feedback. Indian Journal of Ophthalmology 68: 1490.

3. Rajab H, Gazal A, Alkattan K (2020) Challenges to Online Medical Education During the COVID-19 Pandemic. Cureus 12.
4. Dujeepa Samaraskera, Denise Li Meng Goh, Su Ping Yeo, Nicola Ngiam, Marion M Aw, et al. (2020) Response and Lessons Learnt Managing the COVID-19 Crisis by School of Medicine, National University of Singapore. Med Ed Publish 9.

5. Dragan Ilic, Rusli Bin Nordin, Paul Glasziou, Julie K Tilson, Elmer Villanueva (2015) A randomised controlled trial of a blended learning education intervention for teaching evidence-based medicine. BMC Med Educ 5: 39.

6. Fawns T, Jones D, Aitken G (2020) Challenging assumptions about "moving online" in response to COVID-19, and some practical advice. MedEdPublish 9(1): 83.

7. Irini Chatziralli, Camila V Ventura, Sara Touhami, Rhianon Reynolds, Marco Nassisi et al. (2020) Transforming ophthalmic education into virtual learning during COVID-19 pandemic: a global perspective. Eye.

8. David Moszkowicz, Henri Duboc, Caroline Dubertret, Damien Roux, Frédéric Bretagno (2020) 'Daily medical education for confined students during coronavirus disease 2019 pandemic: A simple videoconference solution', Clinical Anatomy 33(6): 927-928.

9. Mohamed H Taha, Mohamed Elhassan Abdalla, Majed Wadi, Husameldin Khalafalla (2020) Curriculum delivery in Medical Education during an emergency: A guide based on the responses to the COVID-19 pandemic. Med Ed Publish 9.

10. Konsil Kedokteran Indonesia (2012) Standar Kompetensi Dokter Indonesia. Jakarta: Konsil Kedokteran Indonesia: 37-38.

11. Kendrick Co Shih, Jonathan Cheuk-Hung Chan, Julie Yun Chen, Jimmy Shiu-Ming Lai (2020) Ophthalmic clinical skills teaching in the time of COVID-19: A crisis and opportunity. Medical Education 54(7): 663-664.

12. Janet W H Sit, Joanne W Y Chung, Meyrick C M Chow, Thomas K S Wong (2005) Experiences of online learning: students' perspective. Nurse Educ Today 25(2): 140-147.

13. Noor M Alqudah, Hisham M Jammal, Omar Saleh, Yousef Khader, Nail Obeidat, et al. (2020) Perception and experience of academic Jordanian ophthalmologists with E-Learning for undergraduate course during the COVID-19 pandemic. Annals of Medicine and Surgery 59: 44-47.

14. He B, Tanya S, Sharma S (2020) Perspectives on virtual ophthalmology education among Canadian medical students. Canadian Journal of Ophthalmology.

15. H D Jeffry Hogg, Michael Pereira, Julian Purdy, Richard J R Frearson, Gordon B Lau (2020) A non-randomised trial of video and written educational adjuncts in undergraduate ophthalmology. BMC Medical Education 20(1): 10.

16. Tony Succar, John Grigg, Hilary A Beaver, Andrew G Lee (2016) A systematic review of best practices in teaching ophthalmology to medical students. Survey of Ophthalmology 61(1): 83-94.

17. Elisabeth Coyne, Hazel Rands, Valda Frommolt, Victoria Kain, Melanie Plugge, et al. (2018) Investigation of blended learning video resources to teach health students clinical skills: An integrative review. Nurse Educ Today 63: 101-107.

18. Garrison DR, Kanuka H (2004) Blended learning: Uncovering its transformative potential in higher education. The Internet and Higher Education 7(2): 95-105.

19. McBride G, Cantillon P (2016) How do undergraduate medical students learn ophthalmology in a clinical environment? British and Irish Orthoptic Journal 13: 40-44.

20. Hill S, Dennick R, Amoaku W (2017) Present and future of the undergraduate ophthalmology curriculum: a survey of UK medical schools. Int J Med Educ IJME 8: 389-395.

21. Tony Succar, John Grigg, Hilary A Beaver, Andrew G Lee (2020) Advancing ophthalmology medical student education: International insights and strategies for enhanced teaching. Survey of Ophthalmology. Elsevier 65(2): 263-271. 
ISSN: 2574-1241

DOI: 10.26717/BJSTR.2021.37.005968

Muhammad Syauqie. Biomed J Sci \& Tech Res

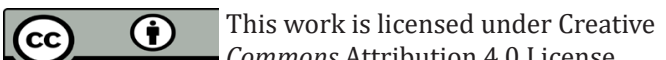

Commons Attribution 4.0 License

Submission Link: https://biomedres.us/submit-manuscript.php

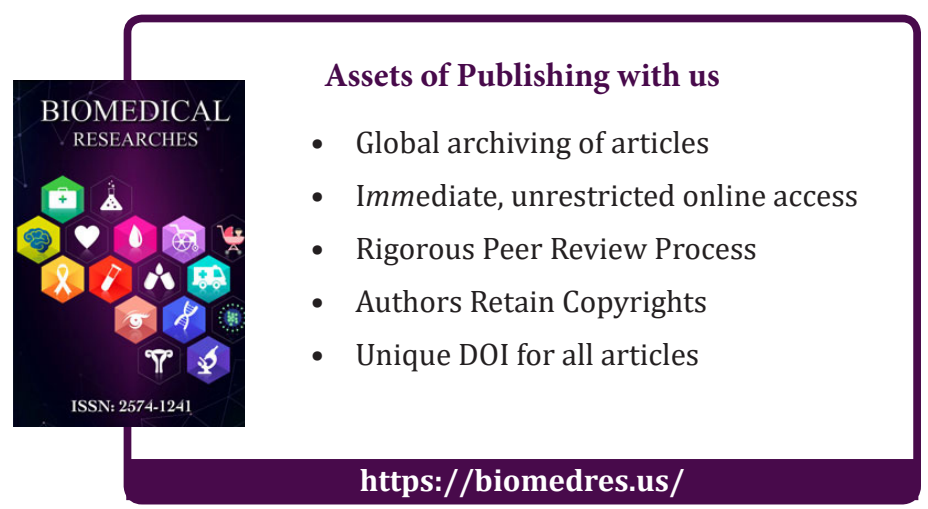

